\title{
Middle Ear Ventilation Tube in Patients with Cleft Palate at King Abdulaziz University Hospital
}

\author{
Talal A. AlKhatib', FRCSC, Yasir S. Jamal'2, FRCS(C), FICS, MD, \\ Abdulaziz H. Alghamdi', MBBS, Bhaa M. Simbawa ${ }^{3}$, MBBS, \\ Yahya H. Ghunaim ${ }^{1}$, MBBS, and Lujain A. Bukhari ${ }^{1}$, MBBS \\ 'Department of Otolaryngology-Head Neck Surgery, ${ }^{2}$ Department of Surgery, Division of Pediatrics, \\ Faculty of Medicine, King Abdulaziz University and ${ }^{3}$ Medical Intern, University of Jeddah, \\ Jeddah, Saudi Arabia
}

\section{Correspondence}

Dr. Talal A. AlKhatib

P.O. Box 80215, Jeddah 21589, Saudi Arabia

e.M: talkhatib@kau.edu.sa

Submission: 15 Feb. 2017

Accepted: 2 Mar. 2017

\section{Citation}

AlKhatib TA, Jamal YS, Alghamdi AH, Simbawa BM, Ghunaim YH, Bukhari LA. Middle ear ventilation tube in patients with cleft palate at King Abdulaziz University Hospital. JKAU Med Sci 2017; 24 (2): 29-32 DOI: 10.4197/Med. 24.2.4

\begin{abstract}
This study aims to determine the number of patients with cleft palate requiring treatment for otitis media with effusion. Speech and hearing assessments were also considered. We conducted a retrospective study from January, 2005 through December, 2012 at King Abdulaziz University Hospital, Jeddah, Saudi Arabia, on otitis media with effusion in patients with cleft palate. We reviewed patients' medical records to determine the number requiring treatment for otitis media with effusion, the timing of middle ear ventilation tube insertion, the number of tubes to be inserted, and the type of tube to be used. Data were collected from the patients'medical records. Ethical approval was obtained by the university's ethical committee. A total of 101 patients were diagnosed with cleft palate spectrum. Among them, we found that only 12 patients had a hearing assessment and tympanograms performed followed by middle ear ventilation tube insertion. This may indicate the need for more involvement of the otolaryngologists in the multidisciplinary clinical teams for evaluating cleft palate patients.
\end{abstract}

\section{Keywords}

Otitis media; Middle ear; Ventilation tube; Cleft palate, Tympanograms; Effusion; Hearing assessment; Speech assessment

\section{Introduction}

left palate (CP) and cleft lip and palate (CLP) are structural malformations that develop during gestation. These anomalies may be present alone or as part of a syndrome, or with other associated abnormalities. The estimated prevalence of orofacial cleft (OFC) has been recorded to be 1 in every 700 neonates worldwide ${ }^{[1]}$. In Saudi Arabia, the prevalence is 0.3 in every 1000 live births ${ }^{[2]}$.

Otitis media with effusion (OME) associated with cleft palate spectrum (CP/CLP) is due to Eustachian tube dysfunction. Otitis media with effusion may lead to hearing loss, and affect linguistics, academics, and personal development if not treated early ${ }^{[3]}$. 
The purpose of our study was to review patients with $\mathrm{CP} / \mathrm{CLP}$ and determine the number requiring OME treatment, the timing of middle ear ventilation tube insertion, the number of tubes to be inserted, and the type of tube to be used. Speech and hearing assessment were also considered, and to re-evaluate the need of pre-operative middle ear evaluation of patients with the cleft palate spectrum and the need for MEVT insertion.

\section{Materials and Methods}

We conducted a retrospective study from January, 2005 until December, 2012 on otitis media with effusion in patients with cleft palate spectrum at King Abdulaziz University Hospital, Jeddah, Saudi Arabia. We examined the patients' medical records, obtaining ethical approval for this study from the King Abdulaziz University Ethics Committee.

\section{Inclusion and Exclusion Criteria}

All hospital records were reviewed. Patients meeting the following inclusion criteria were enrolled:

- Age 0-25 years

- Cleft palate (CP)and cleft lip and palate (CL/CLP) but not cleft lip only

- Undergone one or more surgical repairs for CP

\section{Data Extraction}

From enrolled patients meeting the inclusion criteria, the following data were extracted when available:

- Patient's age, sex, type of cleft, associated deformities

- Type of surgery, speech assessment, hearing assessment

- Tube insertion during initial surgery, tube insertion after the development of complications, the number of tubes inserted, and the type of the tube used.

\section{Results}

Of 101 patients enrolled, 41 (40.59\%) CP patients, 60 (59.41\%) patients had CLP, of those 22 (21.78\%) patients had CP and bilateral cleft lip, 40 (37.62\%) patients had $\mathrm{CP}$ and unilateral cleft lip. Among 101 patients, we found out that only $12(11.88 \%)$ patients who were diagnosed with cleft palate spectrum had a hearing assessment \pm tympanograms performed and followed by middle ear grommet tube insertion. Among patients with middle ear ventilation tube insertion (MEVT), one patient had type $C$ tympanogram, eight patients had type $B$ tympanogram and three patients were not assessed by tympanogram preoperatively. The number of MEVT inserted was bilateral in $10(83.33 \%)$ patients and unilateral in two (16.67\%) patients.

\section{Discussion}

Otitis media with effusion is a common complication in patients with cleft palate due to poor function of the eustachian tube ${ }^{[4]}$. As a consequence of persistent OME in these patients, conductive hearing loss is gradually developed, which affects their hearing abilities and speech and usually requires surgical intervention ${ }^{[5]}$.

We included 101 patients with cleft palate with or without cleft lip in our retrospective study. Only 12 patients had MEVT and a hearing assessment but tympanograms were done pre-operatively in only nine patients.

A review of the literature yielded several studies supporting MEVT insertion in patients with CP/CLP such as Szabo et al.'s retrospective study published in 2010; conducted on patients with a cleft palate with or without a cleft lip born between $1^{\text {st }}$ January 2000 and $31^{\text {st }}$ December 2005, 86 patients with cleft palate spectrum by the age of 5 years old were reported in this study. Eighty-four (97.67\%) patients received at least one set of ear tubes for persistent middle ear fluid with conductive hearing impairment while only two $(2.33 \%)$ patients received no tubes ${ }^{[6]}$. Huang et al. ${ }^{[7]}$ in a randomized control trial published in 2012 examining the effect MEVT surgery in cleft palate children with secretory otitis media, found tympanostomy to aid in improving the cure rate of OME in children with cleft palate; moreover, the younger the patient is, the better the degree of middle ear function recovery. The retrospective study of Klockars and Rautio ${ }^{[8]}$ published in 2012 reported that early tympanostomy tube placement should be considered in children with $\mathrm{CP} / \mathrm{CLP}$ to prevent the incidence of OME and its complications ${ }^{[8]}$. In our current study, only 12 out of 101 patients had hearing assessment \pm tympanograms (9 patients), which indicate the importance of involving the otolaryngologists in pre-operative assessment of patients with $\mathrm{CP}$ spectrum and possible participation in the management of the middle ear dysfunction and the sequalea. 


\section{Conclusion}

Patients with cleft palate spectrum need proper evaluation of the middle ear and its function. Involving the otolaryngologist in the multidisciplinary OFC will prevent middle ear pathology, which might result from the associated middle ear dysfunction and utilize MEVT insertion for protection of the middle ear when indicated.

Future studies should evaluate patients who did not receive MEVT and compare their hearing outcomes to those who had MEVT. The most important recommendation is proper assessment of CP spectrum by an otolaryngologist. This can be achieved by good cooperation between pediatric, plastic and otolaryngology surgeons.

\section{Conflict of Interest}

The authors have no conflict of interest.

\section{Disclosure}

None of the authors received any type of commercial support either in forms of compensation or financial for this study. They have no financial interest in any of the products or devices, or drugs mentioned in this article.

\section{Ethical Approval}

Obtained.

\section{References}

[1] [No authors listed]. Global registry and database on craniofacial anomalies: Report of a WHO Registry Meeting on Craniofacial Anomalies. Mossey P, Castilla E. eds. Geneva, Switzerland: WHO, 2003.

[2] Al-Johar A, Ravichandran K, Sunbhani S, Al-Jarba E, Almalaq A, Essam AS. Cleft lip palate and craniofacial anomalies registry, Annual Report 2009. King Faisal Specialist Hospital and Research Centre, Riyadh, Saudi Arabia, 2009.

[3] Kuo CL, Lien CF, Chu CH, Shiao AS. Otitis media with effusion in children with cleft lip and palate: a narrative review. Int J Pediatr Otorhinolaryngol 2013; 77(9): 14031409.

[4] Smith TL, DiRuggiero DC, Jones KR. Recovery of eustachian tube function and hearing outcome in patients with cleft palate. Otolaryngol Head Neck Surg 1994; 111 (4): 423-429.

[5] Hubbard TW, Paradise JL, McWilliams BJ, Elster BA, Taylor $\mathrm{FH}$. Consequences of unremitting middle-ear disease in early life: otologic, audiologic, and developmental findings in children with cleft palate. N Eng J Med 1985; 312(24): 1529-1534.
[6] Szabo C, Langevin K, Schoem S. Mabry K. Treatment of persistent middle ear effusion in cleft palate patients. Int J Pediatr Otorhinolaryngol 2010; 74(8): 874-877.

[7] Huang M, Zhao S, Li Y, Peng X, Kuang Y, Long S. [The effect of tympanostomy tube surgery in cleft palate children with secretory otitis media]. Lin Chung Er Bi Yan Hou Tou Jing Wai Ke Za Zhi 2012; 26(22): 1017-1019.

[8] Klockars T, Rautio J. Early placement of ventilation tubes in cleft lip and palate patients: does palatal closure affect tube occlusion and short-term outcome? Int J Pediatr Otorhinolaryngol 2012; 76(10): 1481-1484. 


\section{مراجعة أنبوب الإذن الوسطى في مرضى العنك المشقوق في مستثفى جامعة الملك عبدالعزيز - جده البوب الون}

طلال أحمد الخطيب'، وياسر صالج جمال'، و وعبدالعزيز حمدان الغامدي'، وبهاء ماهر سمباوة"، ويحيى

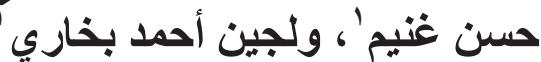

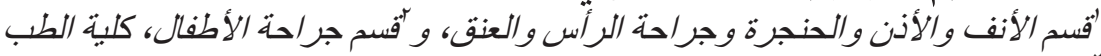

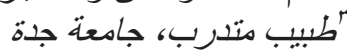
جلة - المدلكة العربية السعودية حلتية

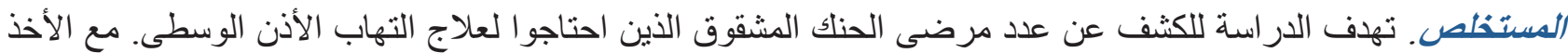

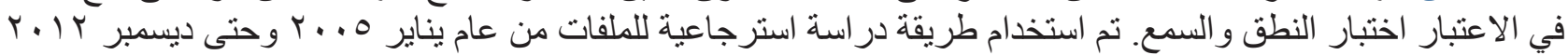

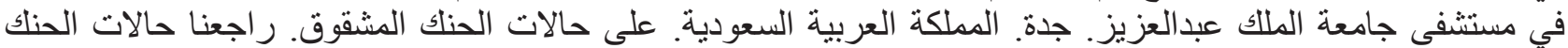

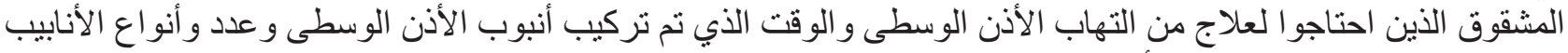

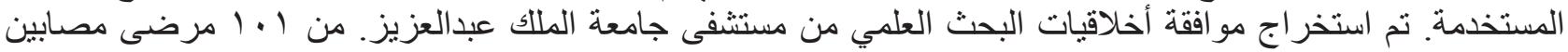

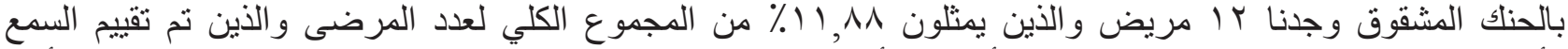

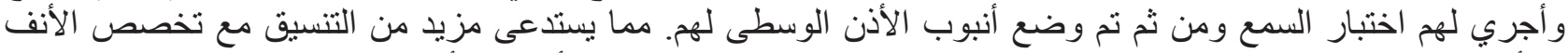

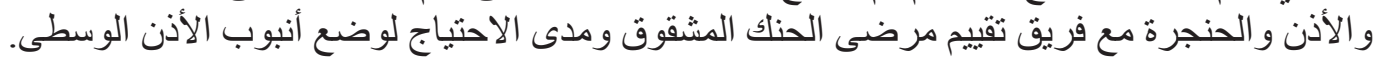

